\title{
A Systematic Review of the Co-occurrence of Gaming Disorder and Other Potentially Addictive Behaviors
}

\author{
Tyrone L. Burleigh ${ }^{1} \cdot$ Mark D. Griffiths $^{1} \cdot$ Alex Sumich $^{2} \cdot$ Vasileios Stavropoulos $^{3} \cdot$ Daria J. Kuss $^{1}$
}

Published online: 7 September 2019

(C) The Author(s) 2019

\begin{abstract}
Purpose of Review The playing of videogames has become an everyday occurrence among many adolescents and emerging adults. However, gaming can be problematic and potentially addictive and problematic gamers can experience co-occurring behavioral or substance use-related problems. The aims of the present review were to (i) determine the co-occurrence of potentially addictive behaviors with problematic and disordered gaming, and (ii) elucidate the potential risk factors in the development and maintenance of co-occurrence within disordered gaming.

Recent Findings The main findings demonstrated that there are few empirical studies $(N=20)$ examining (i) co-occurrence of gaming disorder with other addictive behaviors; (ii) longitudinal risk of disordered gaming with co-occurring addictive behaviors; and (iii) mechanisms of co-occurrence in disordered gaming with co-occurring potentially addictive behaviors. Results suggest that disordered gaming can co-occur with a variety of other addictive behaviors (e.g., alcohol use disorder or addictive use of social media), and that research into the co-occurrence of addictive behaviors and substance use is increasing.

Summary Based on this systematic review, findings suggest that gamers engage in a number of potentially addictive behaviors and substance use which can have detrimental effects on health and wellbeing. While a majority of the reviewed studies consider prevalence rates from a range of geographical locations, there are fewer papers which investigate individual and environmental risk factors.
\end{abstract}

Keywords Gaming disorder $\cdot$ Internet gaming disorder $\cdot$ Comorbidity $\cdot$ Video game addiction $\cdot$ Problematic gaming $\cdot$ Substance use $\cdot$ Systematic review $\cdot$ Co-occurrence

\section{Introduction}

Research has begun to investigate the negative consequences of problematic video gaming in an effort to improve screening, assessment, definition, and treatment of the disorder [1]. Such work has contributed to the American Psychiatric Association (APA) [2] including Internet Gaming Disorder (IGD) as a form of behavioral addiction (warranting further

This article is part of the Topical Collection on Technology Addiction

Tyrone L. Burleigh

tyrone.burleigh@ntu.ac.uk

1 International Gaming Research Unit, Psychology Department, Nottingham Trent University, Nottingham NG1 4FQ, UK

2 Department of Psychology, Nottingham Trent University, Nottingham, UK

3 Cairnmillar Institute, Hawthorn East, Melbourne, Australia investigation) in the latest (fifth) edition of the Diagnostic and Statistical Manual of Mental Disorders (DSM-5) in "Section 3" ("Emerging measures and models"). The World Health Organization [3] has also recognized "gaming disorder" (GD) as an official disorder with addiction like properties in the eleventh revision of the International Classification of Diseases (ICD-11).

Prior to the inclusion of GD in the DSM-5 and ICD-11, several other terms were used to describe problematic video gaming including videogame addiction, pathological video gaming, gaming use disorder, and gaming use dependency [4-7]. Further confusing the issue, online problematic gaming has also been included within the umbrella terms of internet addiction, problematic internet use, and pathological internet use [8-10]. However, the internet addiction umbrella term encompasses several other problematic online activities, such as online gambling, online sex, social media use, and online shopping [11]. In order to maintain consistency throughout the present review, the term "disordered gaming" will be used to 
describe a range of similar and/or overlapping addictive, compulsive, and/or problematic gaming behaviors. When referring to clinically defined cases, the term "GD" will be used, in line with DSM-5 and ICD-11. Furthermore, in relation to other potentially addictive behaviors, the term "problematic" will be used to describe subclinical conditions that do not fully meet all the criteria in the DSM-5 or ICD-11 (e.g., problematic gambling), while the term "disordered" will be used to describe clinical conditions that meet the requisite criteria in the DSM-5 and ICD-11.

There has been a growing body of research suggesting that disordered gaming is associated with a number of other mental health disorders, such as depression [12], anxiety [11], problematic substance use [13], and personality disorders [14]. However, an understudied area in this field is the cooccurrence of disordered gaming with other potentially addictive substances and behaviors. Within the present review, cooccurrence refers to when two or more potentially addictive behaviors (behavioral and/or substance) are engaged in concurrently. For example, in a systematic review on the prevalence of eleven different types of addictions, it was estimated that approximately $10 \%$ of adults with internet addiction may experience another concurrent problematic behavior or substance use (e.g., alcohol use or dependence or gambling addiction [15]).

Evidence supports the co-occurrence of addiction for both substances and behaviors (i.e., the presence of a behavioral addiction increases the propensity for addiction to develop for other behaviors). Indeed, this may create a cycle of reciprocity, wherein mutual exacerbation occurs between two or more problematic behaviors [16-18]. Moreover, those who do experience co-occurring problematic and addictive behaviors are at higher risk of poor mental health (e.g., depression) and physical health [18-20].

In addition, co-occurring problematic behaviors interact to exacerbate clinical symptoms, which can complicate accurate assessment and treatment of other psychiatric disorders [21]. Likewise, disordered gaming may mask problematic substance use which could hinder diagnostic assessment. Alternatively, disordered gaming may exacerbate problematic substance use, causing symptoms of both to alternate which can impact treatment efficacy [22]. This highlights that the assessment and treatment of GD should have a broader focus by not only considering the presenting primary problematic behavior or substance use and symptoms, but also any potential co-occurring addictive behaviors or substance use, which may enforce a cycle of reciprocity.

Consequently, clinicians need to be aware of how potentially addictive behaviors impact or enforce various aspects of a primary problematic behavior (e.g., disordered gaming), and be aware of how co-occurring addictions may impact the onset, course, and outcomes of interventions. Previous literature has demonstrated that the prevalence of co-occurring addictions can be high [15], suggesting that studies which consider addiction as only comprising one specific behavior may be limited in ecological invalidity because individuals have more complex and varied histories of disordered behaviors and co-occurrence [17].

Although there has been one previous comprehensive review investigating the co-occurrence of eleven behavioral and substance addictions, this mainly evaluated US studies, did not examine disordered gaming, and was written almost a decade ago [15]. Furthermore, this review was limited to clinical measures in relation to co-occurrence, and did not consider any proxy measures (e.g., time spent engaging in the activity as an indication of problematic or disordered behavior). Consequently, given the large increase in research examining disordered gaming in the past decade, there is a need for a contemporary systematic review examining the cooccurrence of GD with other potentially addictive behaviors. While several studies have considered the impact of cooccurrence of neurodevelopmental and mood disorders on the onset, course, and maintenance of GD [23], there is limited integrative research examining addiction comorbidities. Furthermore, failure to integrate treatments which consider co-occurring addictions may lead to a "ping pong effect," wherein an individual may bounce back and forth between problematic or disordered behaviors and/or substance use and treatment programs [24].

There are several studies within the behavioral and substance addiction literature that support the efficacy and benefits of treating co-occurring addictions concurrently [24, 25]. Therefore, in order to integrate contemporary research, it is important to conduct a systematic review highlighting extant findings concerning the co-occurrence of addictive behaviors, which specifically considers problematic and disordered gaming and not the often-used broader construct of "internet addiction." This may aid in the development of effective models that identify and aid clinicians to treat disordered gaming alongside other co-occurring addictive behaviors.

The primary goal of the present study was to review empirical research over the past decade, providing up-to-date information that considers the impact of addiction to other behaviors on GD, and to provide recommendations for future research. More specifically, the aims of the present review were to (i) determine the co-occurrence of potentially addictive behaviors with problematic and disordered gaming, and to (ii) elucidate the potential risk factors in the development and maintenance of co-occurrence within GD.

\section{Methods}

A systematic review was employed to examine the cooccurrence of potentially addictive behaviors with disordered gaming. While disordered gaming has been conflated with 
internet addiction in the past, it is important to note that only papers that considered assessed gaming and/or gaming disorder (i.e., problematic gaming) were considered. A systematic review contains key elements, such as an overview of the literature, summary of the findings, dissemination of outcomes, and identification of gaps in the literature [26]. The present review utilized a five-stage model of conducting a rigorous systematic review, which included (i) identifying the research question, (ii) identifying relevant studies, (iii) study selection, (iv) dissemination of outcomes, and (v) summarizing and reporting the results [26].

The inclusion criteria for the present review were as follows: (i) empirical studies containing primary data, (ii) studies that assessed the co-occurrence of and potential "cross-addiction" or "addiction hopping" within the problematic or disordered gaming literature; (iii) studies published in peerreviewed journals, (iv) written in English, and (v) published within the past decade. ProQuest, Scopus, and Web of Science were searched, including the following databases: PsychARTICLES, PsychINFO, Scopus, Web of Science Core Collection, and MEDLINE. The search included a number of terms related to disordered gaming that have been used over the past decade. In addition to this, several terms were developed to explore cross-addiction and co-occurrence in the behavioral addiction literature, which led to the following search strategy: (patholog* OR problem* OR addict* OR compulsive OR dependen* OR disorder* OR excess*) AND (video gam* OR computer gam* OR internet gam* OR online gam*) AND ("cross addiction" OR "addiction hopping" OR "expression hopping" OR "substitution hypothesis" OR "switching hypothesis" OR "co-occur*" OR comorbid* OR "dual diagnosis"). Each study's title, abstract, and paper content were screened for eligibility. The full texts of potentially relevant studies were retrieved and screened for eligibility.

A total of 4160 papers were identified in the initial search. The ProQuest database contained 2507 papers (PsychARTICLES $n=1749$; PsychINFO $n=799$ ); Scopus contained 1271 papers; and Web of Science contained 341 papers. Duplicate studies were removed, leaving a total of 3915 papers. These papers had their journal of publication, titles, and abstracts screened, resulting in the exclusion of 3845 papers that were not relevant to the present review, leaving a total of 70 papers, which were eligible for further review. Of these, 54 were excluded as they were not written in English $(n=3)$, did not asses disordered gaming $(n=15)$, did not assess cross-addiction or co-occurrence $(n=16)$, did not consider disordered gaming in conjunction with another behavioral or substance addiction/disorder $(n=17)$, or were review papers $(n=3)$. The remaining 16 papers were considered eligible for further analysis as they met all the inclusion criteria. Furthermore, four additional relevant papers were included from the reference lists of the identified papers, bringing the total to 20 papers. The present paper followed the Preferred
Reporting Items for Systematic Reviews and Meta-Analyses guidelines (PRISMA statement; Moher, Liberati, Tetzlaff, Altman, \& the PRISMA Group, 2009), which includes the use of a PRISMA flow diagram (see Fig. 1).

\section{Results}

The 20 papers that met the inclusion criteria were divided into specific categories. A total of 16 papers were considered as papers that had assessed co-occurrence prevalence of problematic or disordered gaming with other addictive behaviors and had explored their commonalities with various related and/or unrelated risk and/or protective factors. Of these 16 papers, ten were categorized as "prevalence of co-occurrence in GD and other potentially addictive behaviors." The papers within this category each featured validated psychometric measures which provided an indication of severity risk for disordered gaming and other potentially addictive behaviors. The other six papers that assessed prevalence were categorized as "proxy indicators of GD prevalence and other potentially addictive behaviors." Unlike the papers in the first category, these papers did not use psychometric measures as a tool to assess severity for both problematic or disordered gaming and the co-occurring problematic or disordered behavior and/ or substance use. Instead, these studies assessed the frequency of the behavior (e.g., sexual activity; "how many times have you engaged in sexual activity in the last week?") or the consumption of substance (e.g., number of alcoholic drinks; "How many alcoholic drinks have you had in the past week?") as an indicator of use and assessment. The remaining four papers were categorized as "assessing the etiology of disordered gaming and other potentially addictive behaviors." These papers investigated specific relationships between GD and the mechanisms which may contribute to the understanding of the development, maintenance, or exacerbation of GDs with other potentially addictive behaviors (e.g., coping strategies and personality factors).

\section{Prevalence of Gaming Disorder Co-occurrence with Other Addictive Behaviors}

Of the ten studies examining prevalence [10, 27-35], six examined adult populations (e.g., general populations), three examined adolescent populations (e.g., middle school students; see Table 1), and one examined both adolescents and adults. Six [27-30, 32, 35] of these studies focused on the cooccurrence of GD with problematic substance use (i.e., nicotine and cannabis use) and alcohol use. While there has been some exploration of other potentially addictive behaviors, such as buying, phone use, eating, gambling, exercise, sexual behavior, and social media use, these were usually a part of a larger investigation of substance use or disordered substance 
Fig. 1 Flow diagram of paper selection process for the systematic review

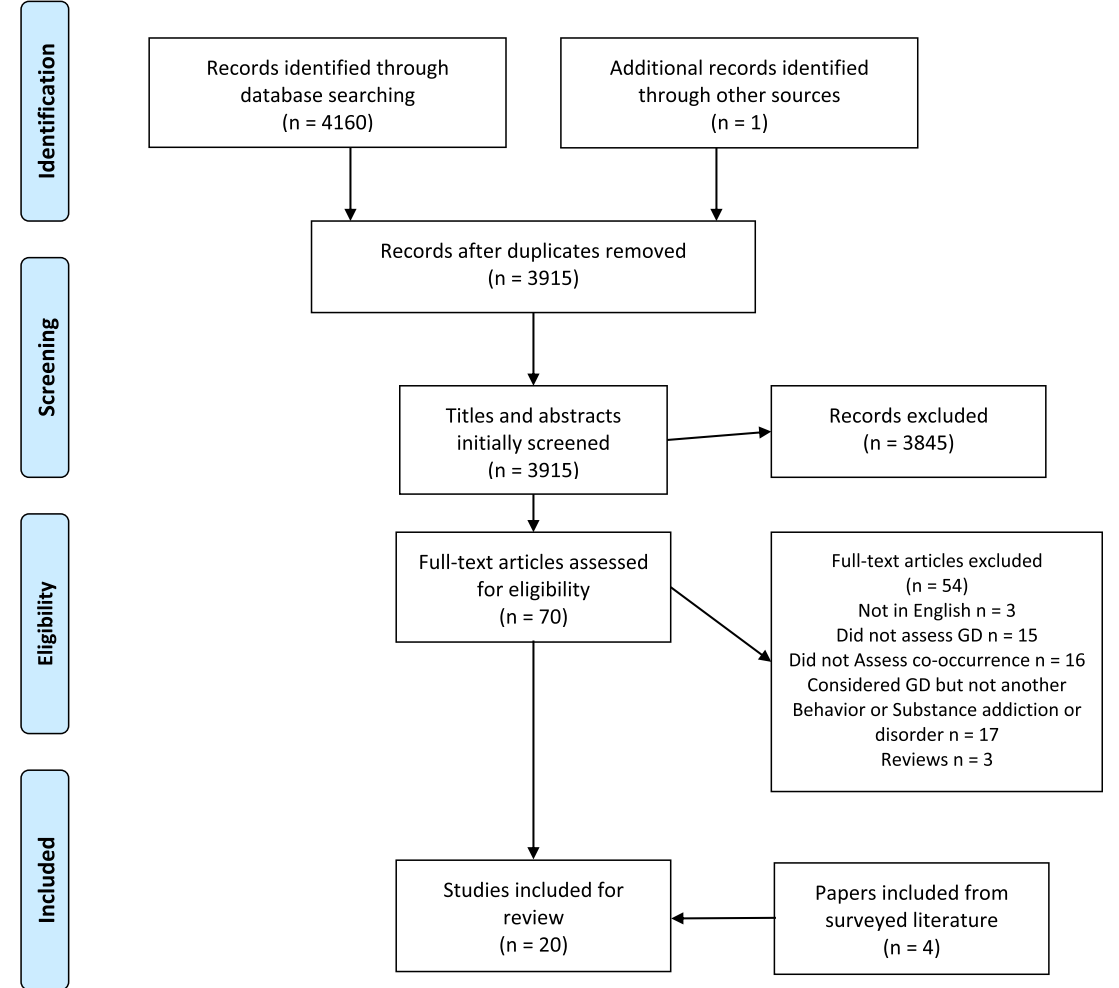

use, which did not consider disordered gaming as the primary focus. Consequently, their findings lack nuanced consideration of disordered gaming and the wider implications within the gaming studies field. Four studies [10, 31, 34, 80] investigated the co-occurrence of GD with other "technological addictions" (e.g., social media addiction and internet addiction).

Prevalence was investigated in eight geographical locations, including Norway $(n=2)[33,35 \cdot]$, Hungary $(n=1)$ [10], Netherlands $(n=1)$ [28], the USA $(n=2)$ [27, 32], Italy $(n=1)$ [34], Germany $(n=1)$ [29], South Korea $(n=1)$ [30], and Portugal $(n=1)$ [31]. Sample sizes ranged from 128 to 21,053 participants. However, the type of surveyed populations was relatively narrow, with the majority of the studies considering school students $(n=5)$, and to a lesser degree the general population $(n=3)$ (see Table 1$)$.

Six studies investigated the prevalence of problematic or disordered gaming within adult populations. Lee et al. [27] investigated the relationship between attention-deficit hyperactivity disorder (ADHD), cigarette smoking, problematic gaming, and the frequency of playing videogames in an online American adult sample $(N=2801)$. Their results suggested that ADHD, cigarette smoking, and frequency of playing videogames had a significant impact on problematic gaming. This finding was consistent with previous studies, such as Ream et al.'s study [32], who found a significant correlation with nicotine, alcohol, caffeine, cannabis use, and problematic videogame use in a large American sample of adult gamers
$(N=2885)$. Furthermore, among gamers, $64 \%$ used caffeine and $41 \%$ of those caffeine users had consumed caffeine while gaming; $26 \%$ of their sample used nicotine and $61 \%$ of smokers had smoked cigarettes while gaming; $34 \%$ of participants consumed alcohol, and $38 \%$ of those had drank alcohol while gaming; and $5.6 \%$ of their sample smoked cannabis and $80 \%$ of those had smoked cannabis while gaming.

Similarly, Na et al. [30] surveyed South Korean adults ( $N=$ 1819) online, and found that $21 \%$ experienced both problematic alcohol use (i.e., scoring over 20 on the Korean version of Alcohol Use Disorders Identification test [AUDIT-K]) and problematic gaming. This group also had higher cigarette smoking rates $(44.8 \%)$ than participants in the problematic alcohol group (31.6\%) or problematic gaming group (26\%), which is consistent with the American sample above. Furthermore, their results indicated that those participants who reported both drinking alcohol and gaming demonstrated higher scores on psychometric tests (which indicated poorer mental health outcomes) than any other group (i.e., control, alcohol group, and gaming group), lending support to the notion that co-occurring substance use and activities and potentially addictive behaviors are associated with maladaptive clinical outcomes [30].

Müller et al. [29] investigated exercise dependence (EXD) in a German sample of participants attending a fitness center $(N=128)$. Their results found that out of the ten males $(7.8 \%)$ who were at risk of developing EXD, two experienced problematic gaming. One participant was at risk of an eating 


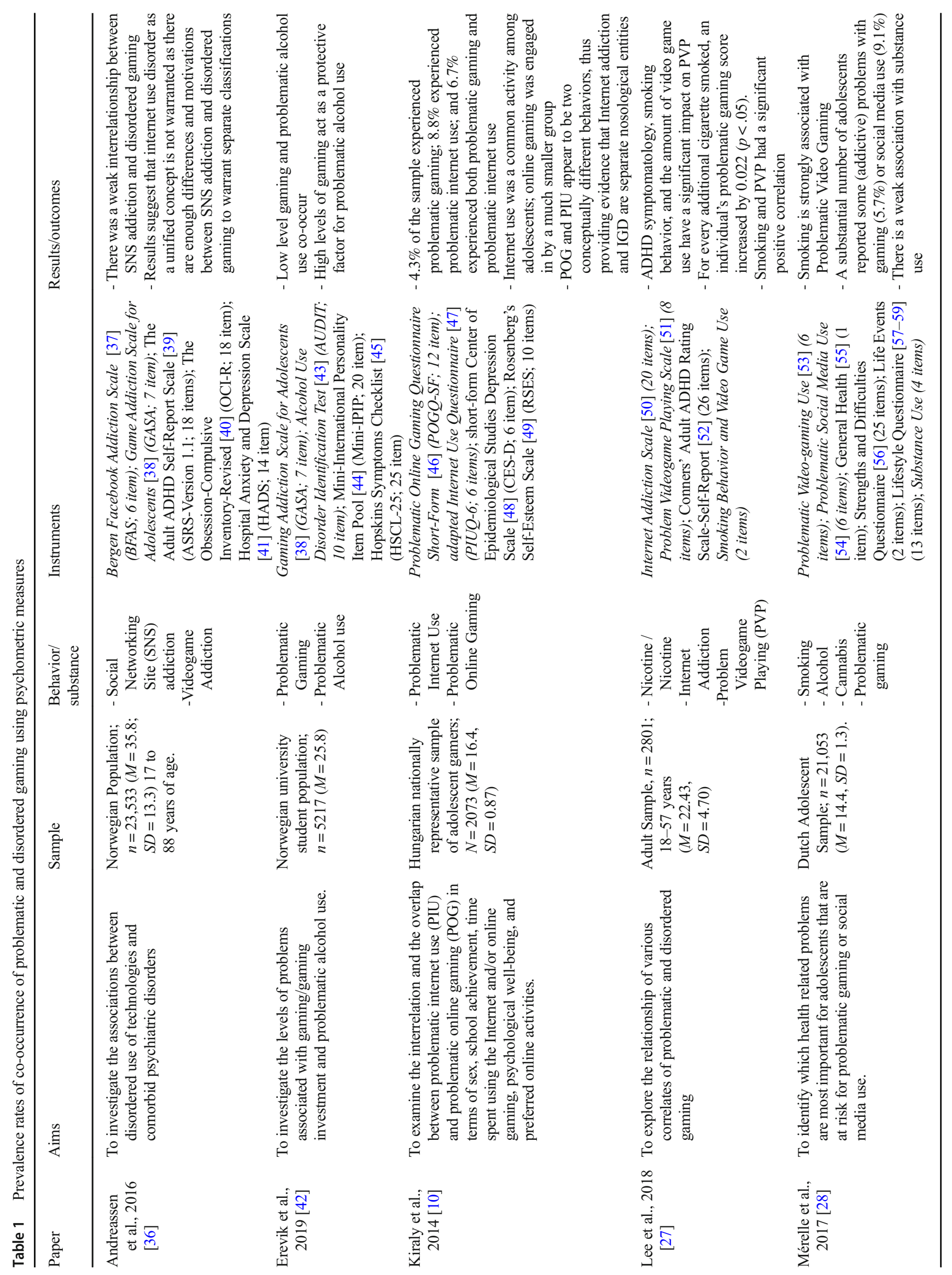




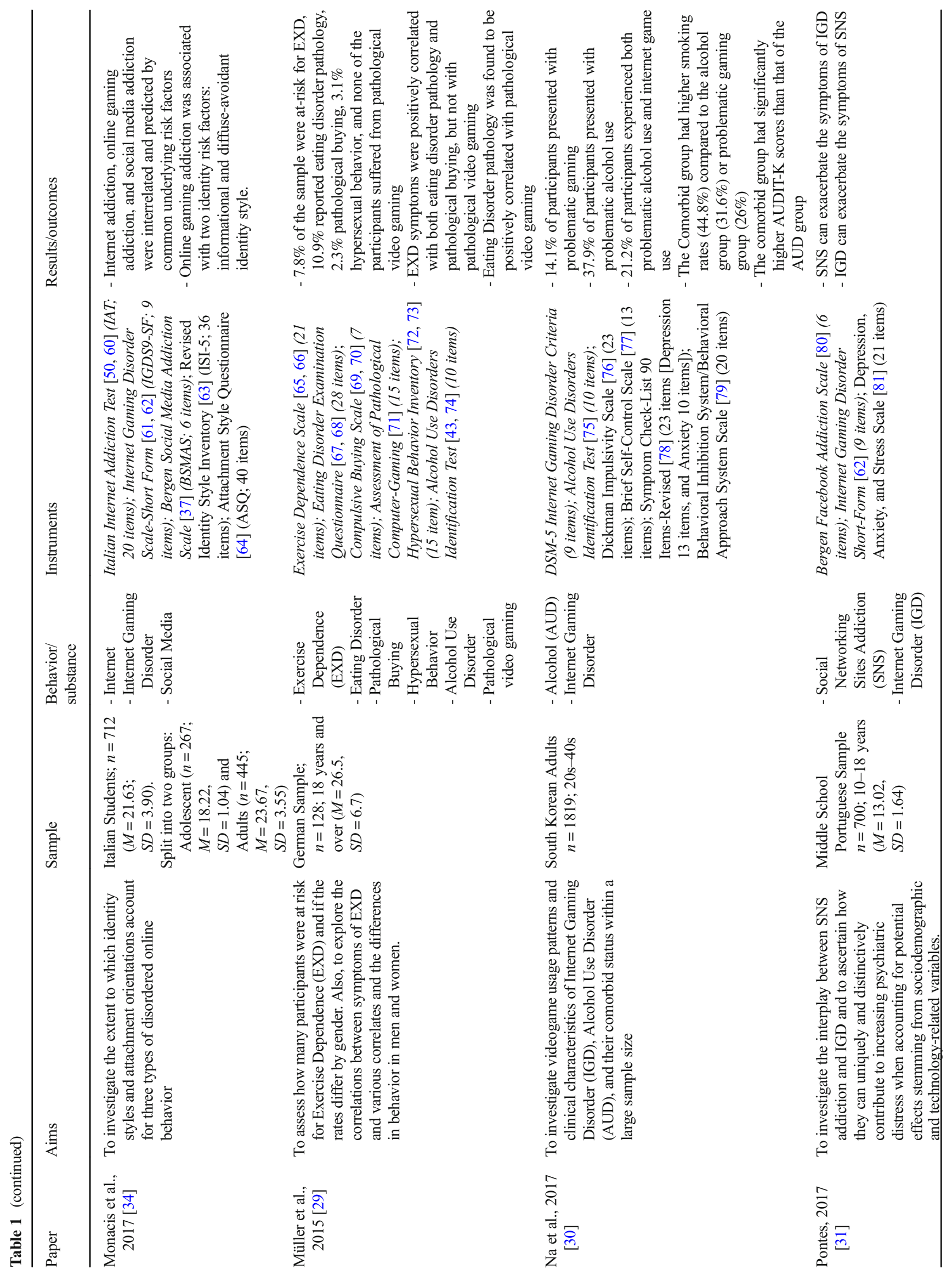




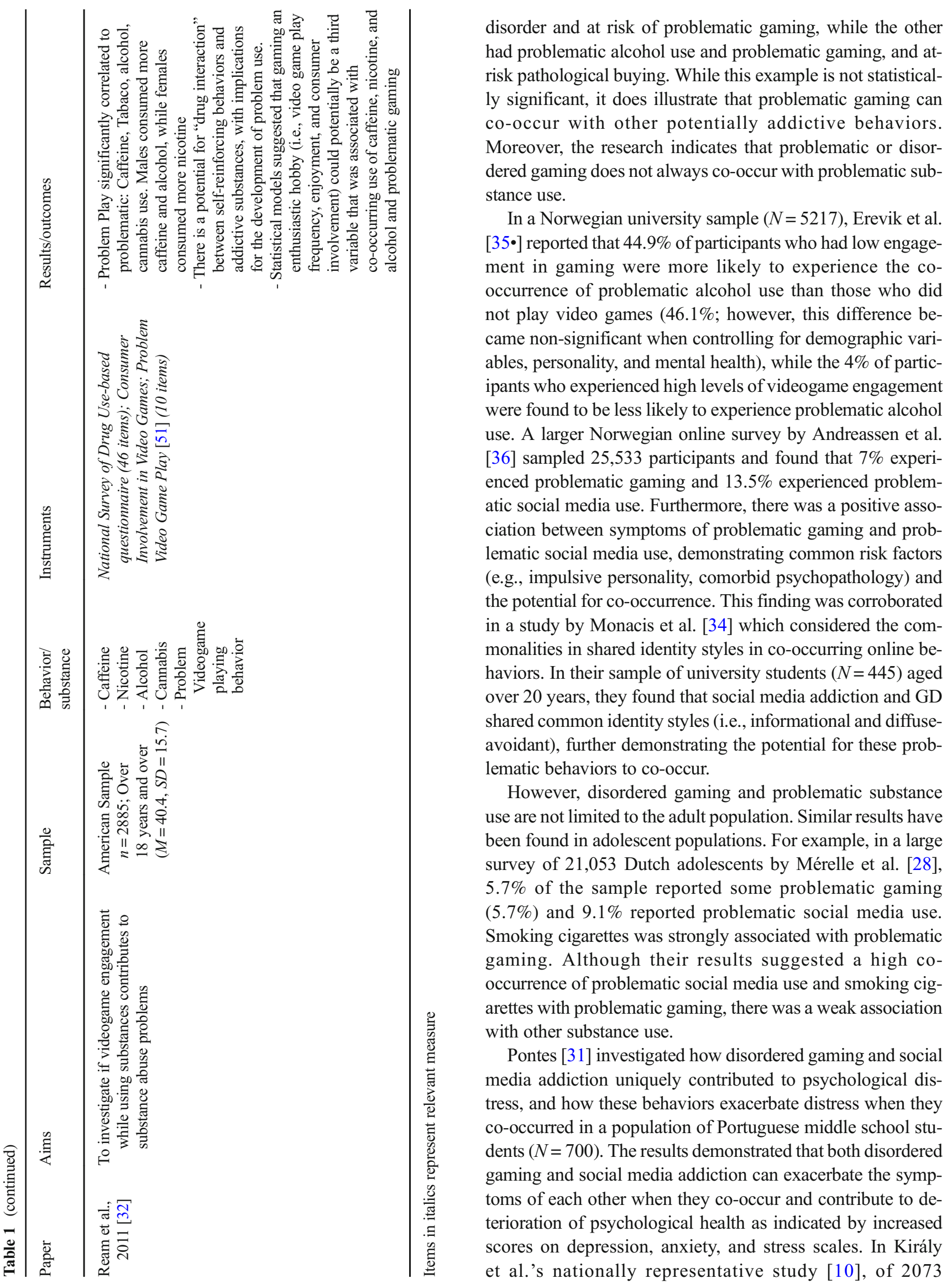


adolescents, $4.3 \%$ experienced problematic gaming, $8.8 \%$ experienced problematic internet use, and $6.7 \%$ experienced both problematic videogame use and internet use. Their results demonstrated an overlap in problematic internet use and problematic gaming but verified that these are two distinct problematic behaviors that have the potential to co-occur with one another, and which may lead to the exacerbation of problematic internet use and/or problematic gaming [31].

\section{Proxy Indicators of Prevalence of Gaming Disorder and Other Potentially Addictive Behaviors}

Other studies have focused on prevalence of disordered gaming and other potentially addictive behaviors using proxy indicators (e.g., using number of alcoholic drinks consumed per day or per week to assess severity of alcohol use). Of the six studies that assessed proxy measures of potentially addictive behaviors [42, 82-87] (Table 2), two studies [84, 99] examined general adult populations (e.g., national surveys) using proxy indictors of problematic use, two $[85,86]$ considered both adolescents and adults, while the latter two $[82,87]$ examined adolescent populations (e.g., secondary school students). A total of five of six studies [82-84, 86, 87] using proxy measures investigated alcohol use and substance use, while four considered smoking cigarettes [82, 84, 86, 87], and one investigated gambling [85]. The geographical locations also varied with papers based in the USA $(n=2)$ [83, 87], Italy $(n=1)$ [82], Canada $(n=1)$ [84], the Czech Republic $(n=1)$ [86], and France $(n=1)$ [85].

In regard to prevalence within the adolescent populations, two studies showed a positive correlation between the frequency of video game use and substance use, demonstrating a strong association [82, 87]. More specifically, Gallimberti et al. [82] found in their adolescent sample $(N=1156)$ that $16.4 \%$ experienced problematic gaming, and within this cohort, $41.2 \%$ had smoked cannabis, $23.2 \%$ had consumed an energy drink (i.e., caffeine), $21.7 \%$ had smoked a cigarette (i.e., nicotine), and $21.3 \%$ had drank alcohol (in their lifetime), demonstrating an association between gaming and use of these substances.

Van Rooij et al. [87] also suggested that higher scores on the Video Game Addiction Test (VGAT; which assesses problematic videogame use) indicated an increase in frequency of substance use. Their research showed that $36.4 \%$ of online gamers in their sample $(n=8478)$ consumed alcohol, $34 \%$ smoked cigarettes, and $44.6 \%$ smoked cannabis. This is in line with studies that exclusively used psychometric measures to asses use and severity of other potential addictions. A similar trend was found in a large sample of Czech online gamers $(N=3952)$ [86] which investigated gamers and the influence of psychoactive substances. They found that while gaming, caffeine was the most frequently used substance $(74.2 \%)$, followed by alcohol $(40.4 \%)$, nicotine $(25.3 \%)$, and illicit substances (14.5\%).
Similarly, Konkolÿ Thege et al. [84] surveyed 6000 adults and found that those who experienced problematic gaming $(2.1 \%), 1.2 \%$ experienced problematic alcohol use, while $31.1 \%$ experienced problematic nicotine use, and $13.5 \%$ experienced problematic cannabis use. This was calculated using a single self-report question "Thinking back over your life, have you ever personally had a problem with [problematic behavior or substance use]?" with 3 possible responses"No," "Yes, but not in the past 12 months," and "Yes, in the past 12 months." Using this question, the researchers also considered potentially addictive behaviors that co-occur with disordered gaming. Their results suggested that $37.2 \%$ of their participants had experienced the co-occurrence of problematic work, $36.6 \%$ had experienced problematic eating behaviors (i.e., eating too little or too much), $14.1 \%$ had experienced problematic sex (i.e., excessive sexual behavior), and $12.3 \%$ had experienced problematic gambling. The latter finding was in line with a study by McBride et al. [85], which reported that $11.4 \%$ of disordered gamers within in their sample experienced problem gambling, and which is consistent within the wider literature [100, 101]. Finally, a study by Ivory et al. [83] on US college students $(n=533)$ suggested that gaming was not significantly associated with nicotine or substance use. However, taken as a whole, the aforementioned studies tend to indicate that disordered gaming appears to frequently cooccur alongside problematic substance use, and there are complex associations between the co-occurring problematic substance use and potential behavioral addictions.

\section{Assessing the Etiology of Gaming Disorder and Co-occurring Potentially Addictive Behaviors}

Four $[7,33,102,103]$ out of the 20 eligible studies identified for review were classified as etiological papers and defined as papers that attempted to explore the underlying mechanisms that may contribute to co-occurrence of GD with other potentially addictive behaviors and possible etiological pathways (see Table 3). These papers also have diverse geographical locations, including Norway [33], Spain [7], Australia [102], and Germany [103].

Dysfunctional coping strategies have been used to explore how underlying cognitive mechanisms contribute to the development and maintenance of co-occurring behavioral and substance addictions and understand etiology. Schneider et al. [102] utilized the Brief COPE [126] to assess different subdomains of coping styles (i.e., a range of cognitive and behavioral responses that are utilized in stressful situations) [127]. They surveyed 823 Australian high school students $(M=14.3, \mathrm{SD}=1.4)$ and found that coping may play a pivotal role when considering co-occurring risk behaviors. They highlighted a tendency toward denial and behavioral disengagement coping styles - which were positively correlated with substance use-within those who scored higher on 


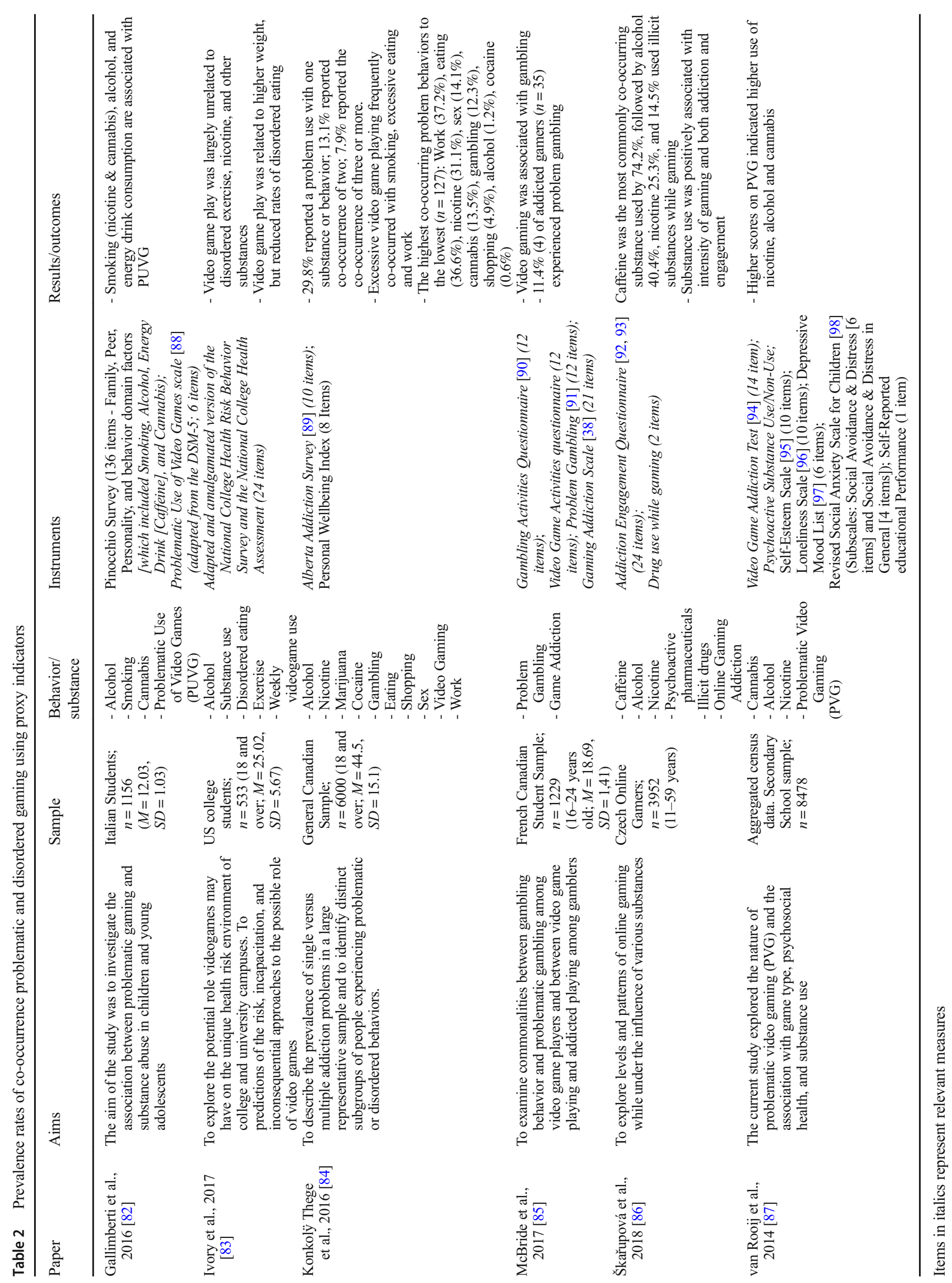




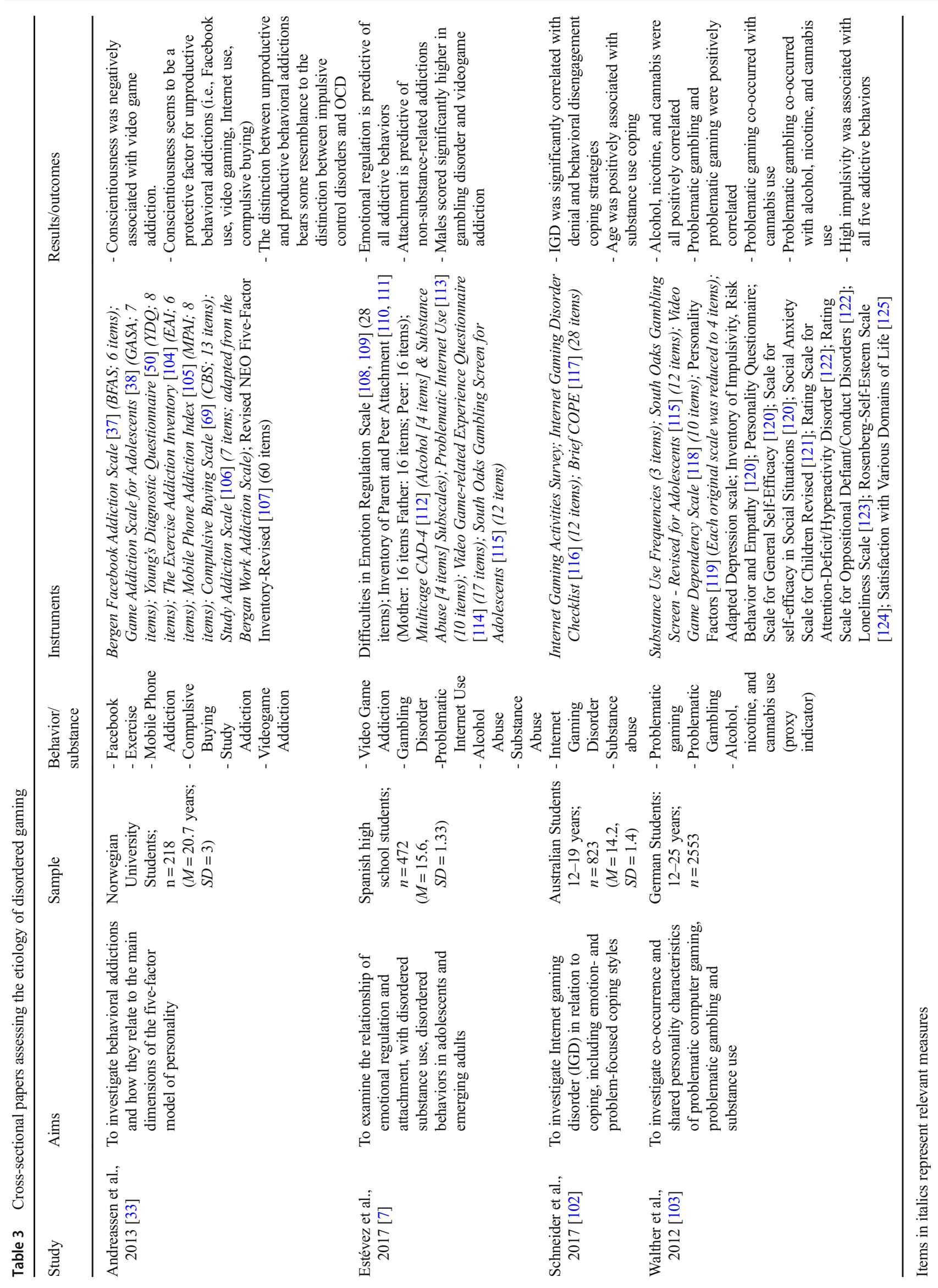


disordered gaming, suggesting that adolescents may employ avoidant coping strategies.

In a sample of 472 Spanish students (aged 13-21 years), Estévez et al. [7] assessed the relationship between emotional regulation and attachment in several addictive behaviors, including disordered gaming. The study found that attachment style was predictive of behavioral addictions, but not substance addictions. Poor peer attachment predicted gaming and gambling disorders, and poor maternal attachment predicted problematic internet use.

With regard to personality, Andreassen et al. [36] found that social media addiction, internet addiction, and disordered gaming were all negatively associated with conscientiousness among a small sample of Norwegian university students $(n=218)$. Walther, Morgenstern and Hanewinkel [103] also proposed that co-occurrence between substance and behavioral addictions could be explained via personality traits. Their results indicated that impulsivity and social anxiety were associated with substance users, gamblers, and gamers. The high impulsiveness trait (i.e., doing things without thinking them through) characterized individuals who engage in problematic substance use, problematic gambling, and problematic gaming. However, while low social anxiety was predictive of problematic substance use and problematic gambling, the reverse was true for problematic gaming, where those with high social anxiety were at higher risk for problematic gaming behavior. It should also be noted that social anxiety has been associated with dysfunctional coping strategies ( [102], which in turn has been implicated in addiction [128, 129]. Furthermore, the researchers noted that while problematic substance users have high co-occurrence to other addictions, each addiction to one substance showed associations with personality traits (i.e., high impulsivity and high extraversion) and mental health problems (e.g., high depression, low social anxiety). Problem gamers showed overlap in some of these traits (i.e., impulsivity and social anxiety) with problematic gamblers.

\section{Discussion}

The aim of the present paper was to review and describe the literature on co-occurrence within the field of gaming disorder (GD) published over the past decade. The review considered the prevalence rates in empirical studies that investigated the potential co-occurrence of potential behavioral addictions and/or substance use in those with GD. It also described the use of psychometrically validated assessment instruments and proxy measures in assessing prevalence rates, as well as the etiological studies that investigated the development and maintenance of co-occurrence of potentially addictive behaviors among those with GD.
Ten papers considered GD and a co-occurring potential behavioral addictions and/or substance use and employed validated psychometric measures to assess the prevalence, frequency, and severity of the behaviors studied. Six papers investigated adult populations $[27,29,30,32,36,130]$, four papers investigated adolescents [10, 28, 31], and one considered both [34].

Ream et al. [32] investigated a North American sample and found that of those who consume psychoactive substances (e.g., nicotine and/or coffee) also engaged in concurrent use of gaming. The surveyed literature also suggested that smoking nicotine or drinking alcohol can have an impact on problematic gaming scores $[27,30]$. The broader literature suggests an overlap between various substance and behavioral addictions, suggesting it is a relatively common occurrence [15] among adults. Collectively, the reviewed literature also demonstrates that adults who play video games engage in concurrent use of psychoactive substances, which may result in co-occurring problematic use and engagement in potentially addictive behaviors.

The surveyed literature on adolescents also reflects a range of prevalence rates. In a nationally representative Hungarian sample, it was shown that $4.3 \%$ experienced problematic gaming, $8.8 \%$ experienced problematic internet use, and $6.7 \%$ experienced both problematic gaming and internet use [84]. Andreassen et al.'s [36] results suggest that $7 \%$ of Norwegian adults reported problematic gaming. A similar result was found among a Dutch sample, which reported $5.7 \%$ of their sample experienced some problematic gaming and $9.1 \%$ reported problematic social media use, both of which were strongly associated with nicotine consumption [28]. Pontes [31] had a similar finding in Portuguese middle school students, which suggested that the co-occurrence of problematic gaming and problematic social media use can lead to the deterioration of psychological health more so than either problematic behavior on its own. The studies also suggest that disordered gaming shares underlying risk factors (e.g., identity styles [34]) with problematic social media use and internet addition, suggesting that co-occurring problematic behaviors may share common identity styles, which act as risk factors in the co-occurrence of problematic online behaviors (i.e., gaming, social media, and internet use).

These results were consistent with the wider literature in regard to the association with potentially addictive behaviors and/or substance use [131, 132], while the findings concerning disordered gaming also showed parallels with other behavioral addictions and substance disorder fields (e.g., gambling $[133,134])$. However, the variation in the consumption of substances or frequency of behaviors within the surveyed literature may indicate that traditional approaches in psychiatric comorbidities [135] and problem behavior theory [13] may not be a viable approach when assessing disordered consumption of substances and resulting behaviors. Gamers 
may instead be making pragmatic choices involving their consumption of substances, which may not be an indication of uncontrolled behavior [86]. For example, having increased amounts of caffeine or using "smart" drugs could be used to provide a competitive edge while gaming, which could be particularly true for those who play games professionally [136]. This may explain why illicit substance use (as opposed to legal substance use) varies in the surveyed literature, because it may be a choice by gamers to prolong their gaming with stimulants such as caffeine or nicotine [83]. However, gamers may choose to consume substances irrespective of videogame participation [86], which would explain the high rate of nicotine use [84] and alcohol use [130] in some samples of gamers. For example, if an individual is trying to quit smoking, they may increase their alcohol consumption (which has been associated with disordered gaming [30]). In an attempt to offset their need for nicotine, they may engage in other potentially addictive behaviors (e.g., alcohol consumption), which may then co-occur with an addiction, such as GD. This suggests an underlying association with disordered substance use, which can be seen in other disordered behaviors, such as gambling disorder $[137,138]$.

Based on the empirical studies reviewed, problematic gamers consume a variety of substances while engaged in videogames. More specifically, while gaming, between $23.3-$ $74.2 \%$ of gamers consumed caffeine [82, 86], 21.7-25.3\% smoked cigarettes [82, 86], 41.2-44.6\% smoked cannabis [28, 82], 21.3-40.4\% consumed alcohol [82, 86], and $14.5 \%$ consumed illicit substances [86]. In regard to problematic and disordered behavior, the findings suggested that problematic gambling [85], problematic shopping, problematic sex, and problematic work [84] were associated with disordered gaming, while disordered exercise was not related [29, 83].

Indeed, the presented evidence suggests that the cooccurrence of potentially addictive behaviors is not uncommon and is associated with a number of maladaptive outcomes for both adults [27] and adolescents [31, 139]. There appears to be a clear divide between the experience of co-occurrence among adults and adolescents. The literature demonstrates that adults with disordered gaming frequently feature cooccurring problematic or disordered substance use (e.g., alcohol use [30, 32, 35]), while disordered eating [29] appears less frequently. However, the opposite appears to be true for adolescents, who appear to experience co-occurring disordered behaviors, such as social media addiction or problematic internet use $[10,31]$. The discrepancy between adults and adolescents may be explained due to the scarcity of available substances due to age-related factors [140] because disordered substance use is seen to increase as adolescents get older [102], allowing them to purchase alcohol or nicotine legally.

It is also worth noting that many of the problematic behaviors co-occurring with disordered gaming are ones that can be performed concurrently with gaming. For example, the surveyed literature shows that problematic exercise and problematic gaming co-occur. This may be attributed to the fact that gaming does not typically facilitate exercise, as gaming is largely a sedentary behavior, whereas exercise requires vigorous physical activity [29], which acts as a protective factor in GD [141]. This idea is also corroborated by the way the literature consistently shows that smoking and alcohol use co-occur with GD [27, 30, 32, 130]. This may arise because the gaming context can facilitate the concurrent use of alcohol and smoking (i.e., nicotine or cannabis), especially if used as part of a coping strategy [30].

Coping strategies were one of the three ways (i.e., (i) coping strategies, (ii) emotional regulation and attachment, and (iii) personality characteristics) in which the development and maintenance of co-occurrence was considered in behavioral and substance addictions. Schneider et al. [102] considered coping strategies to be a key element in the development and maintenance of co-occurrence in an adolescent sample. Their results suggested that behavioral disengagement was a common coping strategy by those who experienced disordered gaming. One proposed reason of this resulting behavior is the self-medication hypothesis. This hypothesis suggests that in addiction-related disorders, individuals use substances in order to overcome painful affective states as well as related mental disorders [142], and this has been a common area of interest in problematic internet use [143, 144]. It may also indicate that maladaptive coping strategies (i.e., emotional avoidance and/or behavioral disengagement) may play a key role in the development of co-occurring behaviors within disordered gaming. Furthermore, when these coping strategies co-occur, it is evident that these strategies will exacerbate disordered gaming symptoms, more so than either one on their own [145]. However, while there has been some literature to suggest that maladaptive coping strategies play an important role in problematic internet use $[8,145]$, further research is needed in the case of disordered gaming.

Estévez et al. [7] suggested that disordered behavior (e.g., disordered gaming) and substance use may be explained utilizing emotional regulation and attachment theory. It has been suggested that low levels of emotional regulation are associated with an increase in risky behaviors, such as GD [146] and substance use [147]. Furthermore, emotional regulation is also predictive of addictive behaviors (but not substance addiction), suggesting that individuals with difficulty in emotional regulation may engage in addictive behaviors such as gaming to avoid (i.e., behavioral disengage) or regulate negative feelings or emotions (i.e., the self-medication hypothesis [7, 145, 148]). Moreover, Estévez and colleagues' research suggests that attachment may also predict co-occurring use, specifically in behaviors that are potentially addictive. Poor peer-attachment was found to predict GD and gambling disorder, and poor maternal attachment predicted problematic internet use. Individuals with a secure attachment are characterized by a self-acceptance of emotional needs. However, an individual with a non-secure attachment style 
may pay little attention to their emotional needs and feel they have a lack of support [7]. This may then cause them to avoid interpersonal relationships [149], lending support to the notion that behavioral addictions may be understood as a form of escape and compensation for poor relationships [150]. Indeed, it could be suggested that individuals employ maladaptive behavioral coping strategies in response to poor emotional regulation or attachment, which may in turn aid in the development and maintenance of co-occurring at-risk behaviors.

Another dimension that has been considered in the development and maintenance of co-occurrence in GD is personality traits and factors. Low conscientiousness has been found to be associated with behavioral addictions (e.g., SNS addiction and GD [33]). This suggests that people who experience problematic or disordered gaming may have low conscientiousness and may have a low priority of duties and obligations [151], lack of planning ability [152], low self-control, weakness for temptations [153], and experience procrastination [154]. This is in line with Walther et al. [103], whose results suggested that individuals that experience problematic or disordered gaming also have high impulsiveness (i.e., a lack of self-control), which has been associated with problematic or disordered behavior, and/or substance use [155]. Furthermore, problematic gamers only shared a small overlap in personality factors with problem gambling (i.e., problematic behavior), even though problematic gambling shares more of an overlap in personality factors with problematic substance use than problematic gaming. However, problematic gamers reported higher scores on ADHD symptoms, high irritability/aggression, high social anxiety, and low self-esteem than any other addiction in Walther et al.'s paper [103], suggesting that gaming may take a unique dispositional position within the examined addictive behaviors here. The aforementioned studies indicate that personality traits or factors may impact the likelihood for co-occurrence to manifest in people experiencing problematic or disordered gaming.

The literature reviewed represents important examples of the next logical step in the progression of research beyond prevalence rates of co-occurrence. Each of the reviewed studies explored either specific psychological, sociological, and/or physiological factors. This in turn can guide future research into presenting a holistic representation of the specific risk factors (e.g., coping strategies and identity styles), which may contribute to developing, maintaining, or exacerbating co-occurring potentially addictive disorders. Furthermore, future research could help inform public policy and guide the development of treatment that encompasses the full clinical presentations of patients. However, only four recent studies $[7,80,102,103]$ have taken the extra step to investigate the etiology and mechanisms of co-occurring disorders.

Understanding these processes is needed to further the understanding of addictive disorders. Nevertheless, the extant findings are beneficial in advancing the field and providing a framework for how to consider the mechanisms of co-occurring addictive behaviors in a multifaceted manner. Furthermore, the present review also highlights the potential for differing mechanisms of action, despite similar observed effects, suggesting that behavioral and substance addictions, and their cooccurrence involve complex processes. In understanding these factors, treatment efficacy may be increased by targeting common etiological mechanisms across multiple disorders (e.g., coping mechanisms [102], or personality factors [103]), much like the direction of the literature within the substance disorders field.

\section{Co-occurrence Within Disordered Gaming Compared to the Substance Disorder Literature}

Arguably, GD is one of the newer behavioral disorders to be investigated. Nevertheless, past substance use disorder literature can be used to provide a reference point on how to advance the co-occurrence research into disordered gaming. The drug and alcohol abuse literature appears to focus on the epidemiology of co-occurrence as it appears to be commonly studied [156], a trend that the GD literature is following. Furthermore, within the substance abuse literature, co-occurring behavioral and substance addictions appear to be commonly considered in both the general and clinical populations $[25,87]$, indicating that the GD literature should also mimic this global approach. In addition, individuals with co-occurring behavioral or substance use disorders (or problematic use) tend to have poorer functioning and treatment outcomes, much like individuals with disordered gaming [156-158]. These findings within the substance use literature are in part facilitated by the longitudinal research investigating the development, maintenance, and remission of each disorder, which the present field of co-occurrence in disordered gaming lacks.

While research on GD focuses on the prevalence and cooccurrence of psychiatric disorders [23], the substance use literature has gone much further by investigating and identifying the epidemiological factors of co-occurrence and the impact cooccurring disorders can have. For example, there have been a number of studies that have investigated a wide range of underlying mechanisms between co-occurring substance use and other disorders such as neurobiological commonalities, genetic markers, temporal changes, and qualitative research focusing on behavioral changes $[159,160]$. Furthermore, the substance use literature has also investigated whether treating one disorder causes the accompanying co-occurring disorder to go into remission, concluding that it can vary depending upon the disorders and individual presentation $[25,161]$. However, when looking to research concerning disordered gaming, this additional step has not yet been made, and the effects of cooccurrence and its impact on course of illness and by type of disorder are not yet known. Additionally, the substance abuse literature has also closely examined the exacerbating effects of multiple co-occurring disorders $[158,162]$. While the research 
on disordered gaming has begun to move in this direction, research on substance use has attempted to separate various dimensions of co-occurrence (e.g., psychiatric disorders, mental health, and social functioning) by controlling for their effects on the primary disorder in question [163].

Finally, when considering treatments, the substance use literature has paved the way for behavioral disorders. There is a general agreement that co-occurring disorders may require an integrated approach $[164,165]$ which consider not just the primary disorder, but also the co-occurring disorder. For example, in a systematic review on people who experiences severe mental illness and co-occurring substance use suggested that motivational interviewing in conjunction with cognitive behavior therapy (CBT; targeting both substance use, and mental health respectively) showed "quality" evidence for reducing substance use and improving mental health than just CBT alone. However, this type of approach is not near the level of acceptance as more traditional treatments (such as CBT), although there are considerable efforts to evaluate its efficacy in the substance use field [24, 162]. In contrast, the research into integrative treatments that targets both disordered gaming and cooccurring addictive disorders is, to the best of authors' knowledge, notably absent from the literature.

\section{Future Research}

A majority of the surveyed literature does not go beyond measures of association and with measures of prevalence being questionable due to overwhelming lack of representativeness of samples. The published literature suggests that there are various behavioral and substance-related addiction disorders that have the potential to co-occur with GD. However, there is very little additional literature that continues to investigate this further. Regarding the co-occurrence of disordered gaming with other behavioral addictions, only a few studies exist, suggesting a cooccurrence with problematic gambling, shopping, and social media use. While there has not been an extensive amount of literature on the co-occurrence prevalence rates of disordered gaming with other addictive behaviors, it has been explored across several geographical locations and cultures, indicating that it is moving in a similar direction of other addiction-related literature (e.g., gambling [157]). However, while it is important that this line of enquiry is followed, it is also important to investigate the etiological aspects of co-occurrence within GD because it is experienced differently across culturally diverse groups of people.

There is a significant gap in the literature when it comes to longitudinal studies that focus on the changes of co-occurring addictive disorders over time. The current literature establishes that co-occurrences between disordered gaming and other addictive-related disorders are common. Furthermore, no paper to the authors' knowledge has investigated whether disordered gaming preceded the onset of another co-occurring addictive disorder or vice versa. It is imperative to understand how co-occurring disorders interact over time in order to develop appropriate treatment methods. Moreover, models for hypothesizing potential treatment frameworks and outcomes, which consider onset or remission of other co-occurring problematic or disordered behavior, would be instrumental in improving potential effectiveness of treatment methods. For example, having confidence that disordered gaming symptoms typically occur within specific substance abuse disorders (e.g., alcohol or cannabis abuse) may allow for a more tailored approach that targets both disordered gaming and the cooccurring use of other behaviors or substances. Future studies should also consider investigating the time of onset in relation to disordered gaming because this would also provide more robust data and allow for more significant conclusions to be drawn.

\section{Substance Use Literature May Act as a Model to Guide Future Research}

A finding that was consistent across both adults and adolescents was that those who presented with problematic or disordered gaming and a co-occurring addiction-related condition consistently reported more severe experiences as assessed using clinical measures [27, 30,31], which is mirrored within the substance abuse literature $[25,166]$. Another way in which the reviewed literature mirrored the substance use literature is the calls for the early intervention for individuals experiencing co-occurring disorders [167], with a number of studies calling for additional early intervention screening measures [30], providing psychoeducation on the co-occurring disorder [27], or considering shared clinical features (e.g., personality factors [33]). These suggestions highlight the need for careful clinical assessment of co-occurring problematic behaviors that may have developed on a subclinical level and, thus, might contribute to the primary disorder.

The momentum of research examining GD more generally has increased and those in the field are engaging in effective efforts to understand the impact of co-occurring addictive behaviors. The substance use literature provides various research frameworks and designs that could be utilized in the future to bring gaming research in line with the wider field of addictive disorders. For example, investigating the nuances between different co-occurring disordered use in clinical samples [25], continuing investigations into prevalence, but expanding and evaluating the epidemiological data of such impacts as onset and remission [22], and establishing clinical trials and protocols that are tailored toward individuals presenting with co-occurring disorders $[25,160]$.

\section{Limitations}

Although the present review identified several important trends within the disordered gaming co-occurrence literature, 
it is subject to limitations. Firstly, methodology used in the review was descriptive and does not quantitatively synthesize data. Although the authors followed a rigorous and transparent review methodology, it still investigates the breadth of literature, rather than its depth, and as such, no statistical conclusions can be drawn from the results. Secondly, the study excluded literature that was not peer-reviewed. Furthermore, the inclusion criteria meant that only English language papers were reviewed, limited by a specific set of databases and search terms. As a result, the authors may have missed relevant studies in other languages or databases. As with any review, screening and selection is always a subjective process and is thus prone to biases. Despite capturing a wide range of research terms in several databases, it is possible that relevant studies may have been missed due to a lack of fit with the inclusion criteria. Finally, considering only the use of papers that were published in the last several years may have also contributed the small amount of papers on co-occurrence and gaming disorder.

\section{Conclusion}

The evidence in the present review suggests an increase in research interest on co-occurrence of other addiction-related behaviors with disordered gaming. However, currently, most research investigates the prevalence rates of co-occurring addiction-related disorders with disordered gaming and frequently demonstrated the potential for co-occurrence between problematic and disordered behaviors and substance use. Various reviewed papers considered novel ways to investigate the potential development and maintenance of problematic and disordered gaming and its co-occurrence, which could be improved further by considering the frameworks and study designs used in the substance addiction disorder literature. Indeed, the research indicates that co-occurrence in problematic and/or disordered gaming is common, and when examining the substance use field as a guide, outcomes may be improved when separate treatment modalities for these cooccurring disorders are offered in combination. While it is not certain how well these treatment models may work in a diverse population, current research consistently calls for trials of multimodal treatment (i.e., using tailored treatments that consider co-occurring behavior or substance use) to take place.

Open Access This article is distributed under the terms of the Creative Commons Attribution 4.0 International License (http:// creativecommons.org/licenses/by/4.0/), which permits unrestricted use, distribution, and reproduction in any medium, provided you give appropriate credit to the original author(s) and the source, provide a link to the Creative Commons license, and indicate if changes were made.

\section{References}

Papers of particular interest, published recently, have been highlighted as:

- Of importance

1. Yau YHC, Crowley MJ, Mayes LC, Potenza MN. Are Internet use and video-game-playing addictive behaviors? Biological, clinical and public health implications for youths and adults. Minerva Psichiatr. 2012;53:153-70.

2. American Psychiatric Association (2014) Diagnostic and statistical manual of mental disorders : DSM-5. https://doi.org/10.1176/ appi.books. 9780890425596.744053

3. World Health Organization. ICD-11 for mortality and morbidity statistics. In: Int. Classif. Dis; 2018. http://id.who.int/icd/entity/ 1448597234

4. Lemmens JS, Valkenburg PM, Peter J. The effects of pathological gaming on aggressive behavior. J Youth Adolesc. 2011;40:38-47. https://doi.org/10.1007/s10964-010-9558-x.

5. Griffiths MD, Meredith A. Videogame addiction and its treatment. J Contemp Psychother. 2009;39:247-53. https://doi.org/10.1007/ s10879-009-9118-4.

6. Grüsser SM, Thalemann R, Griffiths MD. Excessive computer game playing: evidence for addiction and aggression? CyberPsychology Behav. 2007;10:290-2. https://doi.org/10. 1089/cpb.2006.9956.

7. Estévez A, Jáuregui P, Sánchez-Marcos I, López-González H, Griffiths MD. Attachment and emotion regulation in substance addictions and behavioral addictions. J Behav Addict. 2017;6: 534-44.

8. Brand M, Laier C, Young KS. Internet addiction: coping styles, expectancies, and treatment implications. Front Psychol. 2014;5. https://doi.org/10.3389/fpsyg.2014.01256.

9. Yung K, Eickhoff E, Davis DL, Klam WP, Doan AP. Internet addiction disorder and problematic use of Google Glass ${ }^{\mathrm{TM}}$ in patient treated at a residential substance abuse treatment program. Addict Behav. 2015;41:58-60.

10. Király O, Griffiths MD, Urbán R, Farkas J, Kökönyei G, Elekes Z, et al. Problematic internet use and problematic online gaming are not the same: findings from a large nationally representative adolescent sample. Cyberpsychology, Behav Soc Netw. 2014;17:749-54.

11. Adams BLM, Stavropoulos V, Burleigh TL, Liew LWL, Beard $\mathrm{CL}$, Griffiths MD. Internet gaming disorder behaviors in emergent adulthood: a pilot study examining the interplay between anxiety and family cohesion. Int J Ment Health Addict. 2018;17:828-44. https://doi.org/10.1007/s11469-018-9873-0.

12. King DL, Delfabbro PH, Zwaans T, Kaptsis D. Clinical features and axis I comorbidity of Australian adolescent pathological Internet and video game users. Aust New Zeal J Psychiatry. 2013;47:1058-67.

13. Ko C, Yen J-Y, Yen C, Chen C, Weng C, Chen C. The association between internet addiction and problematic alcohol use in adolescents: the problem behavior model. CyberPsychology Behav. 2008;11:571-6.

14. Schimmenti A, Infanti A, Badoud D, Laloyaux J, Billieux J. Schizotypal personality traits and problematic use of massivelymultiplayer online role-playing games (MMORPGs). Comput Human Behav. 2017;74:286-93.

15. Sussman S, Lisha N, Griffiths M. Prevalence of the addictions: a problem of the majority or the minority? Eval Health Prof. 2011;34: 3-56.

16. Haylett SA, Stephenson GM, Lefever RMH. Covariation in addictive behaviours: a study of addictive orientations using the shorter PROMIS questionnaire. Addict Behav. 2004;29:61-71.

17. Gossop M. A web of dependence. Addiction. 2001;96:677-8. 
18. Martin RJ, Usdan S, Cremeens J, Vail-Smith K. Disordered gambling and co-morbidity of psychiatric disorders among college students: an examination of problem drinking, anxiety and depression. J Gambl Stud. 2014;30:321-33.

19. Urbanoski KA, Castel S, Rush BR, Bassani DG, Wild TC. Use of mental health care services by Canadians with co-occurring substance dependence and mental disorders. Psychiatr Serv. 2007;58: 962-9. https://doi.org/10.1176/appi.ps.58.7.962.

20. Burleigh TL, Stavropoulos V, Liew LWL, Adams BLM, Griffiths MD. Depression, internet gaming disorder, and the moderating effect of the gamer-avatar relationship: an exploratory longitudinal study. Int J Ment Health Addict. 2018;16:102-24.

21. Najt P, Fusar-Poli P, Brambilla P. Co-occurring mental and substance abuse disorders: a review on the potential predictors and clinical outcomes. Psychiatry Res. 2011;186:159-64.

22. Freimuth M, Waddell M, Stannard J, Kelley S, Kipper A, Richardson A, et al. Expanding the scope of dual diagnosis and co-addictions: behavioral addictions. J Groups Addict Recover. 2008;3:137-60.

23. Ko C-H, Yen J-Y, Yen C-F, Chen C-S, Chen C-C. The association between internet addiction and psychiatric disorder: a review of the literature. Eur Psychiatry. 2012;27:1-8.

24. Burdzovic Andreas J, Lauritzen G, Nordfjærn T. Co-occurrence between mental distress and poly-drug use: a ten year prospective study of patients from substance abuse treatment. Addict Behav. 2015;48:71-8.

25. Morisano D, Babor TF, Robaina KA. Co-occurrence of substance use disorders with other psychiatric disorders: implications for treatment services. NAD Publ. 2014;31:5-25.

26. Siddaway AP, Wood AM, Hedges LV. How to do a systematic review: a best practice guide for conducting and reporting narrative reviews, meta-analyses, and meta-syntheses. Annu Rev Psychol. 2019;70:747-70.

27. Lee HJ, Tran DD, Morrell HER. Smoking, ADHD, and problematic video game use: a structural modeling approach. Cyberpsychology, Behav Soc Netw. 2018;21:281-6.

28. Mérelle SYM, Kleiboer AM, Schotanus M, Cluitmans TLM, Waardenburg CM, Kramer D, et al. Which health-related problems are associated with problematic video-gaming or social media use in adolescents? A large-scale cross-sectional study. Clin Neuropsychiatry. 2017;14:11-9.

29. Müller A, Loeber S, Söchtig J, Te Wildt B, De Zwaan M. Risk for exercise dependence, eating disorder pathology, alcohol use disorder and addictive behaviors among clients of fitness centers. J Behav Addict. 2015;4:273-80.

30. Na E, Lee H, Choi I, Kim D-JD-J. Comorbidity of internet gaming disorder and alcohol use disorder: a focus on clinical characteristics and gaming patterns. Am J Addict. 2017;26:326-34.

31. Pontes HM. Investigating the differential effects of social networking site addiction and Internet gaming disorder on psychological health. J Behav Addict. 2017;6:601-10.

32. Ream GL, Elliott LC, Dunlap E. Playing video games while using or feeling the effects of substances: associations with substance use problems. Int J Environ Res Public Health. 2011;8:3979-98.

33. Andreassen C, Griffiths MD, Gjertsen SR, Krossbakken E, Kvam $\mathrm{S}$, Pallesen S. The relationships between behavioral addictions and the five-factor model of personality. J Behav Addict. 2013;2:90-9.

34. Monacis L, De Palo V, Griffiths MD, Sinatra M. Exploring individual differences in online addictions: the role of identity and attachment. Int J Ment Health Addict. 2017;15:853-68.

35. Erevik EK, Torsheim T, Andreassen CS, Krossbakken E, Vedaa $\varnothing$, Pallesen S (2019) The associations between low-level gaming, high-level gaming and problematic alcohol use. Addict Behav Reports 100186 This article is important as it provided novel insight in the way gaming can also act as a protective factor in co-occurning problematic substance use.
36. Andreassen C, Billieux J, Griffiths MD, Kuss DJ, Demetrovics Z, Mazzoni E, et al. The relationship between addictive use of social media and video games and symptoms of psychiatric disorders: a large-scale cross-sectional study. Psychol Addict Behav. 2016;30: 252-62.

37. Andreassen CS, Torsheim T, Brunborg GS, Pallesen S. Development of a Facebook addiction scale. Psychol Rep. 2012;110:501-17. https://doi.org/10.2466/02.09.18.PR0.110.2. 501-517.

38. Lemmens JS, Valkenburg PM, Peter J. Development and validation of a game addiction scale for adolescents. Media Psychol. 2009;12:77-95. https://doi.org/10.1080/15213260802669458.

39. Kessler RC, Adler L, Ames M, et al. The World Health Organization adult ADHD self-report scale (ASRS): a short screening scale for use in the general population. Psychol Med. 2005;35:245-56.

40. Foa EB, Huppert JD, Leiberg S, Langner R, Kichic R, Hajcak G, et al. The obsessive-compulsive inventory: development and validation of a short version. Psychol Assess. 2002;14:485-96.

41. Bjelland I, Dahl AA, Haug TT, Neckelmann D. The validity of the hospital anxiety and depression scale. J Psychosom Res. 2002;52: 69-77.

42. Kircaburun K, Griffiths MD. The dark side of internet: preliminary evidence for the associations of dark personality traits with specific online activities and problematic internet use. J Behav Addict. 2018;7:993-1003.

43. Babor TF, Higgins-Biddle JC, Saunders JB, Monteiro MG (2001) The alcohol use disorders identification test guidelines for use in primary care. Organ. Mund. la Salud.

44. Donnellan MB, Oswald FL, Baird BM, Lucas RE. The mini-IPIP scales: tiny-yet-effective measures of the big five factors of personality. Psychol Assess. 2006;18:192-203. https://doi.org/10. 1037/1040-3590.18.2.192.

45. Derogatis LR, Lipman RS, Rickels K, Uhlenhuth EH, Covi L. The Hopkins symptom checklist (HSCL): a self-report symptom inventory. Behav Sci. 1974;19:1-15. https://doi.org/10.1002/bs. 3830190102.

46. Pápay O, Urbán R, Griffiths MD, Nagygyörgy K, Farkas J, Kökönyei $G$, et al. Psychometric properties of the problematic online gaming questionnaire short-form and prevalence of problematic online gaming in a national sample of adolescents. Cyberpsychology, Behav Soc Netw. 2013;16:340-8. https://doi. org/10.1089/cyber.2012.0484.

47. Demetrovics Z, Szeredi B, Rózsa S. The three-factor model of internet addiction: the development of the problematic internet use questionnaire. Methods: Behav. Res; 2008.

48. Radloff LS. The CES-D scale: a self-report depression scale for research in the general population. Appl Psychol Meas. 1977;1: 385-401. https://doi.org/10.1177/014662167700100306.

49. Winch RF, Rosenberg M. Society and the adolescent self-image. Soc Forces. 2006;44:255. https://doi.org/10.2307/2575639.

50. Young KS. Internet addiction: the emergence of a new clinical disorder. CyberPsychology Behav. 1998;1:237-44.

51. Tejeiro Salguero RA, Bersabé Morán RM. Measuring problem video game playing in adolescents. Addiction. 2002;97:1601-6. https://doi.org/10.1046/j.1360-0443.2002.00218.x.

52. Conners CK, Erhardt D, Epstein JN, Parker JDA, Sitarenios G, Sparrow E. Self-ratings of ADHD symptoms in adults I: factor structure and normative data. J Atten Disord. 1999;3:141-51. https://doi.org/10.1177/108705479900300303.

53. Meerkerk G-J, Van Den Eijnden RJJM, Vermulst AA, Garretsen HFL. The compulsive internet use scale (CIUS): some psychometric properties. CyberPsychology Behav. 2008;12:1-6. https://doi. org/10.1089/cpb.2008.0181. 
54. van Rooij AJ, Ferguson C, Van de Mheen D, Schoenmakers TM. Problematic internet use: comparing video gaming and social media use (conference abstract). J Behav Addict. 2015;4:1-62.

55. DeSalvo KB, Bloser N, Reynolds K, He J, Muntner P. Mortality prediction with a single general self-rated health question: a metaanalysis. J Gen Intern Med. 2006;21:267-75. https://doi.org/10. 1111/j.1525-1497.2005.00291.x.

56. Muris P, Meesters C, van den Berg F. The Strengths and Difficulties Questionnaire (SDQ). Eur Child Adolesc Psychiatry. 2003;12:1-8.

57. American Academy of Pediatrics. Committee on public education (2001) American academy of pediatrics: children, adolescents, and television. Pediatrics.

58. Kemper HCG, Ooijendijk WTM, Stiggelbout M (2000) Consensus over de Nederlandse norm voor gezond bewegen. Tijdschr. voor gezondheidswetenschappen.

59. Martens M, van Assema P, Brug J. Why do adolescents eat what they eat? Personal and social environmental predictors of fruit, snack and breakfast consumption among 12-14-year-old Dutch students. Public Health Nutr. 2005;8:1258-65. https://doi.org/10. 1079/phn2005828.

60. Fioravanti G, Casale S. Evaluation of the psychometric properties of the Italian internet addiction test. Cyberpsychology, Behav Soc Netw. 2015;18:120-8.

61. Monacis L, de Palo V, Griffiths MD, Sinatra M. Validation of the Internet Gaming Disorder Scale - Short-Form (IGDS9-SF) in an Italian-speaking sample. J Behav Addict. 2016;5:683-90.

62. Pontes HM, Griffiths MD. Measuring DSM-5 internet gaming disorder: development and validation of a short psychometric scale. Comput Human Behav. 2015;45:137-43.

63. Monacis L, de Palo V, Sinatra M, Berzonsky MD. The revised identity style inventory: factor structure and validity in Italian speaking students. Front Psychol. 2016;7. https://doi.org/10. 3389/fpsyg.2016.00883.

64. Fossati A, Feeney JA, Donati D, Donini M, Novella L, Bagnato $\mathrm{M}$, et al. On the dimensionality of the attachment style questionnaire in Italian clinical and non clinical participants. J Soc Pers Relat. 2003;20:55-79.

65. Hausenblas HA, Downs DS. How much is too much? The development and validation of the exercise dependence scale. Psychol Heal. 2002;17:387-404. https://doi.org/10.1080/ 0887044022000004894

66. Müller A, Claes L, Smits D, Gefeller O, Hilbert A, Herberg A, et al. Validation of the German version of the exercise dependence scale. Eur J Psychol Assess. 2013;29:213-9. https://doi.org/10. 1027/1015-5759/a000144.

67. Fairburn CG, Beglin SJ. Assessment of eating disorder psychopathology: interview or self-report questionnaire. Int J Eat Disord. 1994.

68. Hilbert A, de Zwaan M, Braehler E. How frequent are eating disturbances in the population? Norms of the eating disorder examination-questionnaire. PLoS One. 2012. https://doi.org/10. 1371/journal.pone.0029125.

69. Faber RJ, O'Guinn TC. A clinical screener for compulsive buying. J Consum Res. 2002;19:459. https://doi.org/10.1086/209315.

70. Mueller A, Mitchell JE, Crosby RD, Gefeller O, Faber RJ, Martin A, et al. Estimated prevalence of compulsive buying in Germany and its association with sociodemographic characteristics and depressive symptoms. Psychiatry Res. 2010;180:137-42. https://doi. org/10.1016/j.psychres.2009.12.001

71. Wölfling K, Müller KW, Beutel M. Reliability and validity of the scale for the assessment of Pathological Computer-Gaming (AICA-S). Medizinische Psychol: Psychother. Psychosom; 2011.

72. Klein V, Rettenberger M, Boom K-D, Briken P (2014) A validation study of the German version of the hypersexual behavior inventory (HBI). Eine Validierungsstudie der Dtsch Version des Hypersexual Behav Invent (HBI)

73. Reid RC, Li DS, Gilliland R, Stein JA, Fong T. Reliability, validity, and psychometric development of the pornography consumption inventory in a sample of hypersexual men. J Sex Marital Ther. 2011;37:359-85. https://doi.org/10.1080/0092623X.2011. 607047.

74. Dybek I, Bischof G, Grothues J, Reinhardt S, Meyer C, Hapke U, et al. The reliability and validity of the Alcohol Use Disorders Identification Test (AUDIT) in a German general practice population sample. J Stud Alcohol. 2006;67:473-81.

75. So K, Sung E. A validation study of the brief Alcohol Use Disorder Identification Test (AUDIT): a brief screening tool derived from the AUDIT. Korean J Fam Med. 2013;34:11.

76. Dickman SJ. Functional and dysfunctional impulsivity: personality and cognitive correlates. J Pers Soc Psychol. 1990;58:95-102. https://doi.org/10.1037/0022-3514.58.1.95.

77. Won S-D, Han C. Reliability and validity of the Korean version of the impaired control scale. Psychiatry Investig. 2018;15:852-60.

78. Kim KI, Kim JH, Won HT. Korean manual of symptom checklist90- revision. Seoul: Jung Ang Juk Sung Publisher; 1984.

79. Kim K, Kim WS. Korean-BAS/BIS scale. Korean J Heal Psychol. 2001;6:19-37.

80. Andreassen CS, Billieux J, Griffiths MD, Kuss DJ, Demetrovics $\mathrm{Z}$, Mazzoni E, et al. The relationship between addictive use of social media and video games and symptoms of psychiatric disorders: a large-scale cross-sectional study. Psychol Addict Behav. 2016;30:252-62.

81. Lovibond PF, Lovibond SH. The structure of negative emotional states: comparison of the Depression Anxiety Stress Scales (DASS) with the Beck depression and anxiety inventories. Behav Res Ther. 1995;33:335-43.

82. Gallimberti L, Buja A, Chindamo S, Rabensteiner A, Terraneo A, Marini E, et al. Problematic use of video games and substance abuse in early adolescence: a cross-sectional study. Am J Health Behav. 2016:40:594-603.

83. Ivory AH, Ivory JD, Lanier M. Video game use as risk exposure, protective incapacitation, or inconsequential activity among university students. J Media Psychol. 2017;29:42-53.

84. Konkolÿ Thege B, Hodgins DC, Wild TC. Co-occurring substance-related and behavioral addiction problems: a person-centered, lay epidemiology approach. J Behav Addict. 2016;5:614 22.

85. McBride J, Derevensky J. Gambling and video game playing among youth. J Gambl Issues. 2017;2016:156-78.

86. Škařupová K, Blinka L, Tápal A. Gaming under the influence: an exploratory study. J Behav Addict. 2018;7:493-8.

87. van Rooij AJ, Kuss DJ, Griffiths MD, Shorter GW, Schoenmakers TM, van de Mheen D. The (co-)occurrence of problematic video gaming, substance use, and psychosocial problems in adolescents. J Behav Addict. 2014;3:157-65.

88. American Psychiatric Association (2014) Diagnostic and statistical manual of mental disorders : DSM-5. https://doi.org/10.1176/ appi.books.9780890425596.744053

89. Konkolÿ Thege B, Colman I, El-guebaly N, Hodgins DC, Patten SB, Schopflocher D, et al. Substance-related and behavioural addiction problems: two surveys of Canadian adults. Addict Res Theory. 2015;23:34-42.

90. McBride J, Derevensky J. Internet gambling behavior in a sample of online gamblers. Int J Ment Health Addict. 2009;7:149-67.

91. American Psychiatric Association (2000) Diagnostic and statistical manual of mental disorders. 4th text revision ed. American Psychiatric Association, Washington.

92. Charlton JP, Danforth IDW. Distinguishing addiction and high engagement in the context of online game playing. Comput Human Behav. 2007;23:1531-48. 
93. Charlton JP, Danforth IDW. Validating the distinction between computer addiction and engagement: online game playing and personality. Behav Inf Technol. 2010;29:601-13.

94. van Rooij AJ, Schoenmakers TM, van den Eijnden RJ, Vermulst AA, van de Mheen D. Video game addiction test: validity and psychometric characteristics. Netw: Cyberpsychol. Behav. Soc; 2012.

95. Rosenberg M. Society and the adolescent self-image. Princeton NJ: Princeton University Press; 1965.

96. Russell D, Peplau LA, Cutrona CE. The revised UCLA loneliness scale: concurrent and discriminant validity evidence. J Pers Soc Psychol. 1980;39:472-80. https://doi.org/10.1037/0022-3514.39. 3.472 .

97. Engels RCME, Finkenauer C, Meeus W, Deković M. Parental attachment and adolescents' emotional adjustment: the associations with social skills and relational competence. J Couns Psychol. 2001;48:428-39. https://doi.org/10.1037/0022-0167.48. 4.428 .

98. La Greca AM, Stone WL. Social anxiety scale for children-revised: factor structure and concurrent validity. J Clin Child Psychol. 2005;22:17-27. https://doi.org/10.1207/ s15374424jccp2201_2.

99. Jiang Z, Shi M. Prevalence and co-occurrence of compulsive buying, problematic internet and mobile phone use in college students in Yantai, China: relevance of self-traits. BMC Public Health. 2016;16:1211.

100. Kessler RC, Hwang I, Labrie R, Petukhova M, Sampson NA, Winters KC, et al. DSM-IV pathological gambling in the national comorbidity survey replication. Psychol Med. 2008;38:1351-60. https://doi.org/10.1017/S0033291708002900.

101. McBride J, Derevensky J. Internet gambling and risk-taking among students: an exploratory study. J Behav Addict. 2012;1: $50-8$.

102. Schneider LA, King DL, Delfabbro PH. Maladaptive coping styles in adolescents with internet gaming disorder symptoms. Int J Ment Health Addict. 2018;16:905-16.

103. Walther B, Morgenstern M, Hanewinkel R. Co-occurrence of addictive behaviours: personality factors related to substance use, gambling and computer gaming. Eur Addict Res. 2012;18:16774.

104. Terry A, Szabo A, Griffiths M. The exercise addiction inventory: a new brief screening tool. Addict Res Theory. 2004;12:489-99.

105. Leung L. Leisure boredom, sensation seeking, self-esteem, and addiction: symptoms and patterns of cell phone use. Mediat Interpers Commun. 2008. https://doi.org/10.4324/ 9780203926864.

106. Andreassen CS, Griffiths MD, Hetland J, Pallesen S. Development of a work addiction scale. Scand J Psychol. 2012;53:265-72. https://doi.org/10.1111/j.1467-9450.2012. 00947.x.

107. McCrae RR, Costa PT. A contemplated revision of the NEO fivefactor inventory. Pers Individ Dif. 2004;36:587-96. https://doi. org/10.1016/S0191-8869(03)00118-1.

108. Gratz K, Roemer L. Multidimensional assessment of emotion regulation and dysregulation. J Psychopathol Behav Assess. 2004;26: 41-54. https://doi.org/10.1023/B:JOBA.0000007455.08539.94.

109. Hervás, Gonzalo; Jódar R (2008) Adaptación al castellano de la Escala de Dificultades en la Regulación Emocional. Clínica y Salud.

110. Armsden GC, Greenberg MT. The inventory of parent and peer attachment: individual differences and their relationship to psychological well-being in adolescence. J Youth Adolesc. 1987;16: 427-54. https://doi.org/10.1007/BF02202939.

111. Gallarin M, Alonso-Arbiol I. Dimensionality of the inventory of parent and peer attachment: evaluation with the Spanish version. Span J Psychol. 2013;16:E55.
112. Pedrero Pérez EJ, Rodríguez Monje MT, Gallardo Alonso F, Fernández Girón M, Pérez López M, Chicharro Romero J. Validación de un instrumento para la detección de trastornos de control de impulsos y adicciones: el MULTICAGE CAD-4. Trastor Adict. 2007;9:269-78.

113. Fargues MB, Lusar AC, Jordania CG, Sánchez XC. Validación de dos escalas breves para evaluar la adicción a Internet y el abuso de móvil. Psicothema. 2009.

114. Chamarro A, Carbonell X, Manresa JM, Munoz-Miralles R, Ortega-Gonzalez R, Lopez-Morron MR, et al. El Cuestionario de Experiencias Relacionadas con los Videojuegos (CERV): Un instrumento para detectar el uso problemático de videojuegos en adolescentes españoles. Adicciones. 2014;26:303-11.

115. Winters KC, Stinchfield RD, Fulkerson J. Toward the development of an adolescent gambling problem severity scale. J Gambl Stud. 1993;9:63-84.

116. Petry NM, Rehbein F, Gentile DA, Lemmens JS, Rumpf HJ, Mößle T, et al. An international consensus for assessing internet gaming disorder using the new DSM-5 approach. Addiction. 2014;109:1399-406. https://doi.org/10.1111/add.12457.

117. Carver CS, Scheier MF, Weintraub KJ. Assessing coping strategies: a theoretically based approach. J Pers Soc Psychol. 1989;56: 267-83. https://doi.org/10.1037/0022-3514.56.2.267.

118. Rehbein F, Psych G, Kleimann M, Mediasci G, Mößle T. Prevalence and risk factors of video game dependency in adolescence: results of a German nationwide survey. Cyberpsychology, Behav Soc Netw. 2010;13:269-77. https://doi.org/10.1089/cyber. 2009.0227.

119. Kandel DB, Davies M. Epidemiology of depressive mood in adolescents: an empirical study. Arch Gen Psychiatry. 1982;39: 1205-12.

120. Stadler C, Janke W, Schmeck K. IVE: Inventar zur Erfassung von Impulsivität, risikoverhalten und empathie bei 9- bis 14-jährigen Kindern : Manual. Göttingen: Hogrefe; 2002.

121. Melfsen SS. Sozial ängstliche Kinder: Untersuchungen zum mimischen Ausdrucksverhalten und zur Emotionserkennung. Marburg: Tectum-Verlag; 1999.

122. Döpfner M, Lehmkuhl G (1998) DISYPS-KJ: Diagnostik-System für psychische Störungen im Kindes- und Jugendalter nach ICD10 und DSM-IV ; klinische Diagnostik - Elternurteil - Erzieherund Lehrerurteil - Selbsturteil ; Manual, 2nd ed. Huber, Bern.

123. Döring N, Bortz J. Psychometrische einsamkeitsforschung: Deutsche neukonstruktion der UCLA loneliness scale. Diagnostica. 1993.

124. von Collani G, Herzberg PY. Eine revidierte Fassung der deutschsprachigen Skala zum Selbstwertgefühl von Rosenberg. Zeitschrift für Differ und Diagnostische Psychol. 2003;24:3-7. https://doi.org/10.1024//0170-1789.24.1.3.

125. Schwarzer R. Skalen zur Erfassung von Lehrer- und Schülermerkmalen: Dokumentation der psychometrischen Verfahren im Rahmen der wissenschaftlichen Begleitung des Modellversuchs Selbstwirksame Schulen. Berlin: Freie Universität Berlin; 1999.

126. Carver CS. You want to measure coping but your protocol' too long: consider the brief cope. Int J Behav Med. 1997;4:92-100.

127. McMahon EM, Corcoran P, McAuliffe C, Keeley H, Perry IJ, Arensman E. Mediating effects of coping style on associations between mental health factors and self-harm among adolescents. Crisis. 2013;34:242-50.

128. Buckner JD, Zvolensky MJ, Farris SG, Hogan J. Social anxiety and coping motives for cannabis use: the impact of experiential avoidance. Psychol Addict Behav. 2014;28:568-74.

129. Gregg L, Haddock G, Emsley R, Barrowclough C. Reasons for substance use and their relationship to subclinical psychotic and affective symptoms, coping, and substance use 
in a nonclinical sample. Psychol Addict Behav. 2014;28: 247-56.

130. Müller M, Montag C. The relationship between internet addiction and alcohol consumption is influenced by the smoking status in male online video gamers. Clin Neuropsychiatry. 2017;14:34-43.

131. Tavolacci MP, Ladner J, Grigioni S, Richard L, Villet H, Dechelotte P. Prevalence and association of perceived stress, substance use and behavioral addictions: a cross-sectional study among university students in France, 2009-2011. BMC Public Health. 2013;13. https://doi.org/10.1186/1471-2458-13-724.

132. Smith JL, Mattick RP, Jamadar SD, Iredale JM. Deficits in behavioural inhibition in substance abuse and addiction: a meta-analysis. Drug Alcohol Depend. 2014;145:1-33. https://doi.org/10.1016/j. drugalcdep.2014.08.009.

133. Griffiths M, Sutherland I. Adolescent gambling and drug use. J Community Appl Soc Psychol. 1998;8:423-7.

134. Griffiths M, Parke J, Wood R. Excessive gambling and substance abuse: is there a relationship? J Subst Use. 2002;7:187-90.

135. Starcevic V, Khazaal Y. Relationships between behavioural addictions and psychiatric disorders: what is known and what is yet to be learned? Front Psychiatry. 2017;8:53.

136. Dance A. Smart drugs: a dose of intelligence. Nature. 2016;531: S2-3.

137. Goudriaan AE, Oosterlaan J, de Beurs E, van den Brink W. Psychophysiological determinants and concomitants of deficient decision making in pathological gamblers. Drug Alcohol Depend. 2006;84:231-9.

138. Cunningham-Williams RM, Cottler LB, Compton WM, Spitznagel EL, Ben-Abdallah A. Problem gambling and comorbid psychiatric and substance use disorders among drug users recruited from drug treatment and community settings. J Gambl Stud. 2000;16:347-76.

139. Bibbey A, Phillips AC, Ginty AT, Carroll D. Problematic internet use, excessive alcohol consumption, their comorbidity and cardiovascular and cortisol reactions to acute psychological stress in a student population. J Behav Addict. 2015;4:44-52.

140. Tsai J, Huh J, Idrisov B, Galimov A, Espada JP, Gonzálvez MT, et al. Prevalence and co-occurrence of addictive behaviors among russian and spanish youth. J Drug Educ. 2016;46:32-46.

141. Liew LWL, Stavropoulos V, Adams BLM, Burleigh TL, Griffiths MD. Internet gaming disorder: the interplay between physical activity and user-avatar relationship. Behav Inf Technol. 2018;37: $558-74$.

142. Khantzian EJ. The self medication hypothesis of addictive disorders: focus on heroin and cocaine dependence. Am J Psychiatry. 1985;142:1259-64. https://doi.org/10.1176/ajp.142.11.1259.

143. Senormanci O, Konkan R, Guclu O, Senormanci G. Evaluation of coping strategies of male patients, being treated in internet addiction outpatient clinic in Turkey. J Mood Disord. 2014;4:14.

144. Tang J, Yu Y, Du Y, Ma Y, Zhang D, Wang J. Prevalence of internet addiction and its association with stressful life events and psychological symptoms among adolescent internet users. Addict Behav. 2014;39:744-7.

145. Kuss D, Dunn TJ, Wölfling K, Müller KW, H dzelek M, Marcinkowski J. Excessive internet use and psychopathology: the role of coping. Clin Neuropsychiatry. 2017;14:73-81.

146. Estévez A, Herrero D, Sarabia I, Jáuregui P. El papel mediador de la regulación emocional entre el juego patológico, uso abusivo de Internet y videojuegos y la sintomatología disfuncional en jóvenes y adolescentes. Adicciones. 2014;26:282-90.

147. Schreiber LRN, Grant JE, Odlaug BL. Emotion regulation and impulsivity in young adults. J Psychiatr Res. 2012;46:651-8.
148. Aldao A, Nolen-Hoeksema S, Schweizer S. Emotion-regulation strategies across psychopathology: a meta-analytic review. Clin Psychol Rev. 2010;30:217-37.

149. Malik S, Wells A, Wittkowski A. Emotion regulation as a mediator in the relationship between attachment and depressive symptomatology: a systematic review. J Affect Disord. 2015;172:428-44.

150. Vollmer C, Randler C, Horzum MB, Ayas T. Computer game addiction in adolescents and its relationship to chronotype and personality. SAGE Open. 2014;4:215824401351805.

151. Andreassen C, Griffiths MD, Hetland J, Pallesen S. Development of a work addiction scale. Scand J Psychol. 2012;53:265-72.

152. Lee D, Kelly KR, Edwards JK. A closer look at the relationships among trait procrastination, neuroticism, and conscientiousness. Pers Individ Dif. 2006;40:27-37.

153. Wang C-C, Yang H-W. Passion for online shopping: the influence of personality and compulsive buying. Soc Behav Personal an Int J. 2008;36:693-706.

154. Verplanken B, Herabadi A. Individual differences in impulse buying tendency: feeling and no thinking. Eur J Pers. 2001;15:S7183.

155. Di Nicola M, Tedeschi D, De Risio L, et al. Co-occurrence of alcohol use disorder and behavioral addictions: relevance of impulsivity and craving. Drug Alcohol Depend. 2015;148:118-25.

156. Kuss D, Griffiths M, Karila L, Billieux J. Internet addiction: a systematic review of epidemiological research for the last decade. Curr Pharm Des. 2014;20:4026-52.

157. Yakovenko I, Hodgins DC. A scoping review of co-morbidity in individuals with disordered gambling. Int Gambl Stud. 2018;18: 143-72.

158. Winkler A, Dörsing B, Rief W, Shen Y, Glombiewski JA. Treatment of internet addiction: a meta-analysis. Clin Psychol Rev. 2013;33:317-29.

159. Szerman N, Martinez-Raga J, Peris L, Roncero C, Basurte I, Vega $\mathrm{P}$, et al. Rethinking dual disorders/pathology. Addict Disord Their Treat. 2013;12:1-10.

160. Ruiz P. Dual disorders: a worldwide perspective. Addict Disord Their Treat. 2017;16:151-4.

161. Kalina K, Vacha P. Dual diagnoses in therapeutic communities for addicts: possibilities and limits of integrated treatment. Adiktologie. 2013;13:144-64.

162. Cleary M, Hunt GE, Matheson S, Walter G. Psychosocial treatments for people with co-occurring severe mental illness and substance misuse: systematic review. J Adv Nurs. 2009;65:238-58. https://doi.org/10.1111/j.1365-2648.2008.04879.x.

163. Grant BF, Goldstein RB, Saha TD, et al. Epidemiology of DSM-5 alcohol use disorder. JAMA Psychiatry. 2015;72:757.

164. Roncero C, Grau-López L, Casas M. Dual disorders. Addict Disord Their Treat. 2017;16:175-9.

165. Carrà G, Bartoli F, Brambilla G, Crocamo C, Clerici M. Comorbid addiction and major mental illness in Europe: a narrative eeview. Subst Abus. 2015;36:75-81.

166. Gossop M, Marsden J, Stewart D. Dual dependence: assessment of dependence upon alcohol and illicit drugs, and the relationship of alcohol dependence among drug misusers to patterns of drinking, illicit drug use and health problems. Addiction. 2002;97:169-78.

167. Staiger PK, Richardson B, Long CM, Carr V, Marlatt GA. Overlooked and underestimated? Problematic alcohol use in clients recovering from drug dependence. Addiction. 2013;108: $1188-93$.

Publisher's Note Springer Nature remains neutral with regard to jurisdictional claims in published maps and institutional affiliations. 